\title{
LA IMAGINACIÓN ALADA O LOS PROCESOS DE AUTORIZACIÓN Y DESAUTORIZACIÓN EN EL CONTEXTO DE LA CENSURA EN JOSEPH ANTON: A MEMOIR ${ }^{1}$
}

\author{
Aurora PIÑEIRO \\ Universidad Nacional Autónoma de México

\begin{abstract}
¿De qué otra forma se puede amenazar que no sea de muerte? Lo interesante, lo original, sería que alguien lo amenace a uno con
\end{abstract} \\ la inmortalidad.
}

Jorge Luis Borges

$\Gamma$

Ires diosas aladas resguardaban la entrada a La Meca: sus templos eran visitados por quienes llegaban o salían de la ciudad y ofrecían tributos a alguna de estas deidades todavía representativas de un pasado nómada y matriarcal, en un mundo en transición hacia lo sedentario y patriarcal. Las tres diosas, al-Lat, al-Manat y al-Uzza, se encontrarían también en el corazón de un debate relacionado con la sura 53 del Corán: Muhammad ibn Abdullah, a quien el mundo occidental conocería después como el profeta Mahoma, bajó un día de la montaña para dictar la mencionada sura 53, que alentaba el culto a estas figuras: «Have you heard of al-Lat and al-Uzza, and al-Manat, the third, the other one? They are the exalted birds, and their intercession is greatly to be desired $»^{2}$ (Rushdie, 2012: 43). Así nos cuenta Salman Rushdie, en Joseph Anton: A Memoir, su versión sobre el inicio de la controversia relacionada con este conjunto de versos que el mismo profeta Mahoma rechazaría tiempo después. El mencionado profeta bajó de la montaña en otra ocasión y, con gran incomodidad, declaró que había sido engañado en su visita previa: el demonio, disfrazado de arcángel, le había dictado los versos sobre las tres diosas y, por lo tanto, la revelación no era divina sino satánica y debía ser extirpada del Corán inmediatamente. Así, esos versos, adquirieron su condición de satánicos y fueron desautorizados, con la siguiente declaración del profeta, citada por Rushdie: «Have you heard of al-Lat and al-Uzza, and al-Manat, the third, the

\footnotetext{
${ }^{1}$ Este artículo es resultado del trabajo realizado en el marco de los siguientes proyectos de investigación: Horizontes teóricos y críticos en torno a la figura autoral contemporánea (clave IN405014-3), del Programa de Apoyo a Proyectos de Investigación e Innovación Tecnológica (PAPIIT), con financiamiento de la DGAPA-UNAM y ¿Corpus auctoris? Análisis teórico-práctico de los procesos de autorización de la obra artístico-literaria como materialización de la figura autorial (FFI2012-33379), que lleva a cabo el Grupo de Investigación Consolidado Cuerpo y Textualidad (2009 SGR 651) de la Universitat Autònoma de Barcelona.

2 «Habéis considerado, pues, alguna vez qué es lo que adoráis en al-Lat y al-Uzza, y en al-Manat, la tercera y última de esta triada? Ellas son las aves ensalzadas, y su interseción es muy deseable» (2012: 56). En todas las citas de la obra en castellano se utilizó la edición de Mondadori, impresa en México.
} 


\section{Aurora Piñeiro}

other one? They are but names that your forefathers invented, and there is no truth in them. Shall God have daughters while you have sons? That would be an unjust division» (Rushdie, 2012: 43$44)^{3}$.

La cita anterior y los acontecimientos que convirtieron a la sura 53 en un texto apócrifo nos invitan a plantearnos una serie de preguntas sobre los procesos de autorización y desautorización relacionados con los libros que hoy llamamos sagrados en distintas tradiciones; nos llevan a examinar los procesos de exégesis que se realizan durante la conformación de dichas obras y sus lecturas posteriores y, en el caso particular de las diosas aquí deslegitimadas, en un mecanismo de sustitución en el que lo múltiple y femenino fue reemplazado por lo monoteísta y masculino. Así se fija un significado que se promoverá como lo verdadero e incuestionable siglos después.

En Los versos satánicos, novela publicada en 1988, Rushdie se plantea éstas y otras preguntas al interior de una obra literaria cuyos juegos interpretativos son múltiples y donde los recursos de distanciamiento en relación con la tradición islámica también son diversos. Uno de los filtros narrativos más importantes consiste en que la figura profética de la novela aparezca en los sueños de uno de los personajes protagónicos, quien está perdiendo la razón a causa de una crisis de fe. Sin embargo, la obra fue acusada de ser un ataque crudo y directo al Islam, al profeta Mahoma y al Corán, y el 14 de febrero de 1989, se declara la fatwa, el edicto que fue traducido como sentencia de muerte, en contra del escritor de origen indio y nacionalidad británica. En ese momento inicia lo que hoy llamamos el Rushdie affair o Caso Rushdie, es decir, el largo peregrinaje de un artista sometido a más de una década de persecución y censura, y el fenómeno publicitario y de diversa índole que se suscitó a lo largo de ese período. Este es, también, el origen de la obra que nos ocupa en el presente artículo: las memorias de Salman Rushdie.

Joseph Anton: A Memoir (2012) es un libro complejo, donde Rushdie aborda un número amplio de temas e implementa más de un juego literario. En esta ocasión me concentraré en el análisis del mismo como una obra donde las convenciones del subgénero memorias se cumplen, en un cierto sentido, pero se ven desbordadas en otros: Rushdie da cuenta de lo sucedido con su vida y su narrativa a partir de la declaración de la fatwa, pero también nos entrega un texto con el que construye una figura de(l) autor como defensor de la libertad de expresión. En el recorrido, el narrador en tercera persona nos comparte una bitácora de las lecturas realizadas y los procesos de escritura del Rushdie novelista; aborda el tema de la identidad y la manera en que el autor articula el concepto de migrante o ser-en-migración; y nos brinda, por último, una definición de literatura que cierra el libro con una vuelta a lo que Rushdie es: un demiurgo de la palabra.

La definición (ya clásica) de autobiografía, brindada por Philippe Lejeune, nos presenta este tipo de escritura como un «relato retrospectivo en prosa que una persona real hace de su propia existencia, poniendo énfasis en su vida individual y, en particular, en la historia de su personalidad»

\footnotetext{
${ }^{3}$ «Habéis considerado, pues, alguna vez qué es lo que adoráis en al-Lat y al-Uzza, y en al-Manat, la tercera y última de esta triada? ¡Cómo! ¿Para vosotros escogeríais sólo varones, mientras que a Él le asignáis hembras? ¡Pues sí que es injusto ese reparto! Estos supuestos seres divinos no son sino nombres vacíos que habéis inventado -vosotros y vuestros antepasados-y para los cuales Dios nunca ha hecho descender autorización» (Rushdie, 2012: 57).
} 
(Lejeune, 1975: 48). El propio Lejeune señala que las memorias, como uno de los géneros vecinos de la autobiografía, no tienen la obligación de hacer un énfasis drástico en la historia de la personalidad o lo individual, lo cual como deslinde de subgéneros presenta ya varios problemas. De entre las variantes de las escrituras del yo, la frontera entre autobiografía y memorias es una de las más difíciles de establecer (los términos incluso se utilizan como sinónimos), y la acotación de Lejeune apunta hacia un rasgo que ha sido tanto positivo como negativo para la valoración de la segunda modalidad. Por un lado, las memorias han gozado de más libertad al no estar restringidas al retrato de la formación de un carácter ejemplar -como sí lo estuvo, muchas veces, la autobiografía de los siglos XVIII y XIX- y, también, al poder admitir una mayor cuota de subjetividad, así como la crónica de época e, incluso, la autoría proveniente de figuras no públicas. Por otro lado, el carácter más restrictivo del subgénero autobiografía, aunque haya implicado el sometimiento a convenciones un poco más rígidas, contribuyó a que la misma fuera juzgada como un discurso de mayor valía o trascendencia que el de otras escrituras del yo. Así, la autobiografía quedó atrapada, como lo estudia, por ejemplo, Francois Dosse, entre lo historiográfico y la ficción; es un discurso híbrido que remite a una «intención de veracidad» (2011: 16), de suyo problemática, y al que se le atribuye menor confiabilidad que a otros discursos historiográficos, pero mayor autoridad que a otras narrativas del yo, como el diario íntimo o el autorretrato.

A lo anterior hay que agregar que, para Lejeune, el pacto autobiográfico requiere de «la identidad de nombre entre autor, narrador y personaje» (1975: 53) y, aunque admite que puede haber algunas excepciones, para este teórico, las excepciones confirman la regla. Joseph Anton: A Memoir, como el subtítulo lo indica, es un ejemplo de memorias (a las que su autor se ha referido también como autobiografía) que, en muchos momentos funcionan en el territorio de la excepción. La primera de estas excepciones es el uso de la tercera persona para narrar la vida de un tal Joseph Anton, quien resulta ser Rushdie, el autor. El pacto autobiográfico se ve temporalmente desestabilizado, pero el propio libro justifica la presencia de este recurso: Joseph Anton es la identidad bajo la que habitó Rushdie durante los años de la fatwa y, de esa manera, la obra nos presenta una triada autor (Rushdie), narrador en tercera persona (que, de forma gradual, asumimos como el Rushdie del presente de la escritura de las memorias), y personaje Joseph Anton (el Rushdie de la década de la fatwa) como un conjunto de entidades narrativamente diversificadas, pero ontológicamente unificadas. El pacto se sostiene, y se hace posible otra manipulación o truco, la de narrar un antes y un después de Joseph Anton. La estrategia de narración en tercera persona le permite a Rushdie-autor ganar distancia crítica y emocional frente a los acontecimientos descritos y, en mi opinión, es una forma adicional de la resistencia política: un contar desde fuera como negativa a entrar en el personaje o volver a utilizar la jaula de una falsa identidad cuya adopción había sido producto de la fatwa.

Sin embargo, el nombre mismo, Joseph Anton, fue elegido por Rushdie, y la configuración es un tributo a dos escritores que el autor admira: Joseph Conrad y Anton Chekhov. Llama la atención este homenaje a dos figuras caracterizadas por escribir en clave realista y, la primera de ellas, 


\section{Aurora Piñeiro}

Conrad, acusada de ser un defensor de la visión imperialista, según Chinua Achebe. Con la elección de nombre, Rushdie, artífice del realismo mágico y de la literatura poscolonial, celebra a dos maestros del realismo y exonera a Conrad de su supuesto pecado de complicidad imperialista.

De la misma manera, Rushdie rinde tributo a los escritores que lo defendieron a lo largo del período de persecución e incluye un ajuste de cuentas con quienes - escritores o no- lo traicionaron. Como Dante en su Infierno, aprovecha para exhibir a quienes, desde su punto de vista, no se atrevieron a dar un paso adelante en la lucha por el derecho a disentir.

Así, resulta claro que en Joseph Anton, como en toda memoria o autobiografía, se narran episodios de lo público y lo privado, pero el énfasis está puesto en el segmento de vida que, en este caso, corresponde a la persecución y sus implicaciones, de forma particular, en la existencia de un artista: los desiertos interiores a los que se enfrenta quien decide seguir creando en las condiciones de inestabilidad emocional y geográfica que la protección de su integridad acarrearon. Estamos frente a una épica de la vocación escritural, donde el narrador cuenta cómo Joseph Anton superó, uno a uno, los bloqueos de escritor, recurriendo a estrategias distintas según la obra en turno: a veces por la promesa a un hijo; en otro momento, por fidelidad a la vocación; en otros más, por la determinación de no ser sometido al silencio.

Joseph Anton es también una bitácora de las lecturas realizadas durante más de una década y, de manera fundamental, un texto que da cuenta del ars poetica de Rushdie, con especial énfasis en Los versos satánicos, pero no sólo respecto a esa novela. En este sentido, la obra juega un papel importante como documento de lectura de autor, o registro de lo que al Rushdie del 2012 le interesó presentar, tal vez fijar, como su lectura de autor, después de una cierta distancia cronológica, y tras el revuelo que varias de sus obras y declaraciones desataron entre distintos grupos de lectores. En $s u$ narrativa sobre la génesis novelística y lectura de autor entran en juego el factor perspectiva individual, el factor tiempo (mirada retrospectiva), y el factor recepción. De ahí que Joseph Anton pueda ser utilizado como uno más, sólo uno más, de los muchos recursos del mosaico, siempre cambiante, de la interpretación.

Además de lo señalado hasta ahora, Joseph Anton rebasa o trastoca, en un nivel muy específico de lo formal, las convenciones que se asocian al género memorias. De entre los recursos que utiliza para llevar a cabo esa transgresión, mencionaré tres. El primero de ellos es el monólogo interior en cursivas, es decir, con una marca tipográfica que indica la presencia de un discurso interior o privado, en primera persona, que puede tener lugar al mismo tiempo que Joseph Anton habla en voz alta, u otro personaje o voz narrativa ha tomado la palabra. Sólo en la primera ocasión en que se usa el recurso, el narrador nos permite ver que lo que aparecerá en cursivas es parte de un monólogo interno del Joseph Anton del presente de la historia; en el resto del libro, exterioridad e interioridad conviven en una misma oración, a veces sin signos de puntuación que establezcan sus fronteras, pero siempre con las cursivas como la clave para descifrar los niveles discursivos. Este recurso novelístico se traslada a la escritura memorialista y permite que el lector tenga acceso a un nivel todavía más 
íntimo de la psique del personaje, se establece una complicidad y se crea, además, un efecto polifónico.

La segunda estrategia formal se desprende de la anterior porque funciona en el nivel del monólogo interior y se hace patente en el texto también vía la utilización de las cursivas pero, en esta ocasión se trata específicamente de la interpolación de cartas ficcionales: las misivas que a Joseph Anton le hubiera gustado escribir y enviar a distintas figuras de la vida pública o del mundo editorial, por ejemplo, a lo largo de esa década, pero que nunca fueron escritas ni enviadas a sus supuestos destinatarios. Lo epistolar se incorpora así, de manera peculiar, a estas memorias, y la presencia de dicho discurso genera varios efectos interesantes. Por un lado, son cartas inexistentes, que declaran de forma abierta su condición fictiva; sólo se escribieron para habitar el mundo textual de Joseph Anton aunque, en el momento de ser puestas por escrito, adquirieron materialidad y pueden, ahora, ser leídas incluso por quienes iban a ser sus destinatarios originales: los narratarios en primer grado que, en el acto de la lectura del libro encarnan o asumen su función de destinatarios de las cartas. El acto de la comunicación epistolar se cumple, pero en una realidad textual híbrida, en principio «no ficcional», que echa mano, con frecuencia, de recursos novelísticos.

Por otro lado, la estrategia anterior se vuelve todavía más ambiciosa cuando las cartas empiezan a dirigirse a personajes alegóricos, representativos de conceptos o grupos de personas. Así nos encontramos con epístolas que inician con «Querida Religión», o «Querido Lector», donde de forma mucho más radical Joseph Anton se dirige en primera persona a los narratarios, rebelándose contra las restricciones que su condición de yo narrado le impone. Esta ruptura se torna descaradamente literaria cuando dicho yo se subdivide en su «Yo de 52 años» quien le escribe a su «Yo de 65 años», edad que sabemos tenía el Rusdie empírico, cuando se publicaron sus memorias. Así, los lectores presenciamos un debate entre los yoes de la obra que, además, transgrede otro importante plano temporal porque, cuando el Rushdie empírico tenía 65 años (en el 2012), Joseph Anton ya había dejado de existir (era un personaje fallecido). En otro momento de la obra, en la carta al (nuevo) «Milenio», vuelve a ocurrir la ruptura deliberada, y ahora confesa, de los planos temporales cuando Joseph Anton impone, en este caso, su más amplio conocimiento del futuro, sobre las restricciones cognoscitivas del personaje llamado Milenio. Anton lo acusa de ser un fraude (por aquello del conteo inexacto de los años) y, le advierte que la verdadera ruptura, el supuesto quiebre «milenario», va a ocurrir un año después, no sólo por razones cronológicas, sino por razones políticas. El escribiente argüye: «And, as I'm writing this from my know-it-all place in the future, I can tell you with complete authority that, what with the US election in November 2000 and the wellknown subsequent events of September 2001, a year from this faux millennium was when the change did come» ${ }^{4}$ (Rushdie, 2012: 588).

\footnotetext{
${ }^{4} \ll \mathrm{Y}$, como escribo esto desde mi lugar omniscio en el futuro, puedo asegurarte con absoluta autoridad que, con las elecciones norteamericanas de noviembre de 2000 y los posteriores y de sobra conocidos sucesos de septiembre de 2001, el cambio se produjo un año después de este falso milenio» (Rushdie, 2012: 637).
} 


\section{Aurora Piñeiro}

Aquí, las transgresiones temporales y cognoscitivas se unen a la prolepsis (irónica, triste), como una estrategia adicional usada en varias ocasiones por el narrador en tercera persona para aludir a la catástrofe del 11 de septiembre ${ }^{5}$, acontecimiento histórico que justifica la redacción de un capítulo extra en estas memorias, dado su vínculo con los temas de la violencia y la intolerancia, a pesar de ser un episodio posterior, también, al fallecimiento de Joseph Anton.

En congruencia con las transgresiones hasta aquí mencionadas, el tercer recurso que desborda las convenciones de la escritura de memorias es de tipo metatextual. En Joseph Anton se analiza el problema de la autenticidad en el género memorias dentro de las propias memorias, por ejemplo, cuando el narrador cuenta que Doris Lessing estaba escribiendo sus memorias y llamó a Joseph Anton para comentarlas:

Rousseau's way, she said, was the only way; you just had to tell the truth, to tell as much truth as possible. But scruples and hesitations were inevitable. [...] I do think of Rousseau, she added, and I hope this book is an emotionally honest work, but is it fair to be honest about other people's emotions? [...] With much giggling she went off to write, encouraging him to do the same (Rushdie, 2012: 375).

El autobiógrafo no sólo se enfrenta al problema de la memoria como facultad falible, sino a una serie de preguntas de orden ético relacionadas con el derecho a desarticular el binomio privado/ público en relación con los otros, y con el ya mencionado aspecto de la intencionalidad que Lejeune asumió como parte del pacto autobiográfico y que está basada en una «intención de honrar la firma» (1975: 51). Si bien Joseph Anton tiene momentos de solemnidad o episodios en los que clama autenticidad o se emprende una búsqueda de trascendencia, el libro encuentra su balance en el uso de recursos metatextuales, como el recién citado, donde las nociones de fidelidad o autenticidad absolutas son deliberadamente puestas en duda por el propio texto. A lo anterior se unen el humor y la ironía, muchas veces autodirigidos, que facilitan el distanciamiento de las tradicionales autobiografías de personajes célebres masculinos de otros siglos, al provocar que la obra adopte tonos variados y manifieste su carácter de artificio. En este sentido, así como en la manera de abordar el tema de la identidad, que aquí exploraré en los párrafos siguientes, Joseph Anton es una autobiografía que puede darse el lujo de existir en un contexto intelectual postestructuralista; es decir, en diálogo no sólo con la novelística del propio Rushdie, sino también con discursos teóricos y críticos que han «destituido al autor de su lugar central como fuente de significado, y minado la noción de sujeto autobiográfico unificado» (Anderson, 2001: 6, traducción mía).

En este mismo tenor, Joseph Anton se separa de las memorias tradicionales por su manera de abordar el tema de la identidad. El narrador define al personaje como un migrante, un sujeto poscolonial que elije construirse no desde lo que Paul Gilroy diagnosticaría como el viejo «trauma

\footnotetext{
${ }^{5}$ Por ejemplo, la referencia a la primera visita del joven Rushdie a Nueva York, cuando el autor visualizó los edificios de la ciudad como «masivos», y como entidades que parecían decir «estamos aquí para siempre» (Rushdie, 2012: 52-53).

${ }^{6}$ «La manera de Rousseau, dijo ella, era la única manera; uno sólo tenía que contar la verdad, contar tanta verdad como fuera posible. Pero los escrúpulos y las vacilaciones eran inevitables. [...] Sí pienso en Rousseau -añadió-, y espero que este libro sea una obra emocionalmente sincera, pero ¿es justo ser sincero con las emociones de los demás? [...] Con muchas risitas, se fue a escribir, animándolo a él a hacer lo mismo» (Rushdie, 2012: 410).
} 
del desarraigo», sino como un ser con raíces múltiples, una identidad que celebra lo heterogéneo como un modo de estar en el mundo:

the migrated self became, inevitably, heterogeneous instead of homogeneous, belonging to more than one place, multiple rather than singular, responding to more than one way of being, more than averagely mixed up. Was it possible to be -to become good at being- not rootless, but multiply rooted? Not to suffer from a loss of roots but to benefit from an excess of them? (Rushdie, 2012: 54) ${ }^{7}$.

Esta visión de la identidad comulga con el discurso posmoderno/ poscolonial: promueve dicha noción como una construcción, la hace más amplia que el vínculo con la nacionalidad o la etnicidad, y la liga a la idea de la transformación constante, a la posibilidad de redefinir cultura, otra vez en palabras de Gilroy, «a través de una reconciliación con el movimiento y la variación compleja y dinámica» (2000: 111, traducción mía). De ahí que se pueda hablar del ser-en-migración, para insistir en los procesos de movimiento y revisión constantes ${ }^{8}$.

Pero uno de los aspectos de mayor importancia en Joseph Anton: A Memoir es cómo el libro contribuye, de forma activa y deliberada, a la construcción de una figura de autor: Rushdie como defensor de la libertad de expresión.

Para Rushdie, el escritor es un ciudadano que cumple una tarea inevitablemente pública y privada: «He had learned from Faiz [Faiz Ahmed Faiz] that the writer's task was to be both public and private, an arbiter both of society and of the human heart» ${ }^{9}$ (Rushdie, 2012: 110). Así, como figura pública y como víctima de una persecución que lo obligó a vivir y crear en la clandestinidad pero, sobre todo, como creyente firme en el derecho a la palabra y a la disensión, el autor declara, en Joseph Anton, igual que en Estocolmo, frente a la Academia sueca, y a propósito del Premio Kurt Tucholsky, que

At the heart of the dispute over The Satanic Verses, he said, behind all the accusations and abuse, was a question of profound importance: Who shall have control over the story? Who has, who should have, the power not only to tell the stories with which, and within which, we all lived, but also to say in what manner those stories may be told? For everyone lived by and inside stories, the so-called grand narratives. The nation was a story, and the family was another, and religion was a third. As a creative artist he knew that the only answer to the question was: Everyone and anyone has, or should have that power (Rushdie, 2012: 360$)^{10}$.

\footnotetext{
${ }^{7}$ «La identidad del emigrado se convertía, inevitablemente, en algo heterogéneo, no homogéneo, algo que pertenecía a más de un sitio, algo múltiple en lugar de singular, algo que respondía a más de una manera de ser, algo más confuso que la identidad del individuo medio. ¿Era posible ser - desarrollar la aptitud de ser- no desarraigado sino múltiplemente arraigado? ¿No padecer la pérdida de las raíces sino beneficiarse de un exceso de ellas?» (Rushdie, 2012: 68-69).

${ }^{8}$ Otra vez, se fortalece el vínculo con la narrativa rushdiana. En Midnight's Children (1981), por ejemplo, el autor hace de su protagonista, Saleem Sinai, la encarnación de la nueva identidad india, dado su milagroso nacimiento en el instante mismo en que tiene lugar la declaración de independencia del país. Sin embargo, esta construcción de Saleem como identidad biológico política unificada es desacreditada por la novela misma cuando se nos revela que el personaje fue intercambiado por otro bebé, en el cunero del hospital. De esta manera, la genealogía que Saleem ha construido a lo largo del texto, su crónica de los orígenes, es suya sólo a través de «la adopción y la experiencia, pero no por la vía de la herencia» (Kane, 1996: 96, traducción mía). El texto sacude las definiciones convencionales de origen vinculadas a las ideas de sangre o raza, y la de sujeto como noción unificada u orgánica.

9 «Había aprendido de Faiz [Faiz Ahmed Faiz] que la tarea del escritor era simultáneamente pública y privada, que debía ser árbitro tanto de la sociedad como del corazón humano» (Rushdie, 2012: 127).

10 «En el eje de la disputa en torno a Los versos satánicos, explicó, detrás de todas las acusaciones e insultos, había una pregunta de profunda importancia: ¿Quién debe tener el control del relato? ¿Quién tiene, quien debería tener, el poder no
} 


\section{Aurora Piñeiro}

Y unas líneas más adelante, en esa misma conversación con los miembros de la academia: «In a free society the argument over the grand-narratives never ceased. It was the argument itself that mattered. The argument was freedom» (Rushdie, 2012: 360) ${ }^{11}$.

Así, la defensa de la libertad de expresión establece complicidad y coherencia con la narrativa del autor Salman Rushdie, no sólo el escritor de Los versos satánicos, sino el creador de por lo menos 16 libros donde la identidad, las relaciones entre oriente y occidente, la entrada de lo nuevo en el mundo, y el poder de la palabra se someten a escrutinio, se ironizan o celebran según sea el caso, con el derecho de la mente libre a pensarlo todo.

Con este poder y compromiso en mente, Rushdie declara al final del libro que el arte perdura más allá de los regímenes de intolerancia, pero los artistas, como seres humanos, necesitan defensores y, de la misma manera en que él fue defendido por sus compañeros de gremio, él, a su vez, lo hará con otros artistas «who pushed boundaries, transgressed and, yes, blasphemed; all those artists who did not allow men of power or the cloth to draw lines in the sand and order them not to cross» (Rushdie, 2012: 628) ${ }^{12}$. Y así ha ocurrido. El 9 de octubre de 2014, por citar una ocasión reciente, en la ceremonia de entrega del Premio PEN Pinter 2014, Rushdie anunció su decisión de compartirlo con el periodista Mazen Darwish, quien se encuentra encarcelado por su trabajo como presidente del Centro sirio para los medios de comunicación y la libertad de expresión, organismo desde donde ha hecho una labor de documentación sobre los abusos a los derechos humanos en Siria, durante los últimos diez años.

Joseph Anton termina con una declaración de principios y una amplia definición de literatura que engloba muchos de los conceptos analizados a lo largo del recorrido. El narrador en tercera persona afirma que es su elección creer en lo humano, en la universalidad de los derechos, las éticas y las libertades (Rushdie, 2012: 626). Cree también en la capacidad del arte de la novela para revelarnos que la naturaleza humana es la gran constante, sin afirmar que haya una definición universal de dicha naturaleza; e insiste en que el ser humano es heterogéneo, múltiple, fracturado y contradictorio (Rushdie, 2012: 627). La literatura, nos dice Rushdie,

\footnotetext{
tried to open the universe, to increase, even if only slightly, the sum total of what it was possible for human beings to perceive, understand, and so, finally, be. Great literature went to the edges of the known and pushed against the boundaries of language, form and possibility, to make the world feel larger, wider, than before (Rushdie, 2012: 628) . $^{13}$.
}

\footnotetext{
sólo de contar los relatos con los que, y dentro de los que, todos vivimos, sino también de decir cómo pueden contarse esos relatos? Porque todo el mundo vivía por medio de relatos y dentro de relatos, las llamadas grandes narraciones. La nación era un relato, y la familia era otro, y la religión era un tercero. Como artista creativo, él sabía que la única respuesta a la pregunta era: Todas y cada una de las personas tienen, o deberían tener ese poder» (Rushdie, 2012: 393394).

11 «En una sociedad libre, la discusión en torno a las grandes narraciones nunca cesaba. Lo importante era la propia discusión. La discusión era la libertad» (Rushdie, 2012: 394).

12 «[E]n situación de necesidad, otros que empujaran límites, que transgredieran, y sí, que blasfemaran; todos esos artistas que no permitían que los hombres en el poder o los hombres con hábito trazaran líneas en la arena y les ordenaran no cruzarlas» (Rushdie, 2012: 679-680).

13 «[I]ntentaba abrir el universo, aumentar, aunque fuera sólo un poco, la suma total de lo que para los seres humanos era posible percibir, comprender y por tanto, en último extremo, ser. La gran literatura llegaba hasta los lindes de lo conocido
} 
Ante la amenaza de muerte, Rushdie responde con la visibilidad del cuerpo y del corpus, con el discurso en voz alta y la continuidad en la creación. Ante los fundamentalismos que desacreditan a las diosas que vigilan la entrada a la ciudad del intelecto, Rushdie defiende a sus propios tres portentos alados: la libertad de expresión, el arte de contar historias y la imaginación.

\section{Referencias bibliográficas}

ANDERSON, L. (2001): Autobiography. Nueva York, Routledge.

Dosse, F. (2011): El arte de la biografía. Entre historia y ficción. Trad. de Marcela Carolina Cinta Vázquez. México, Universidad Iberoamericana.

FLOOD, A. (2014): «Salman Rushdie to Share PEN Pinter Prize with Mazen Darwish», The Guardian, en http://www.theguardian.com/books/2014/oct/10/salman-rushdie-share-penpinter-prize-mazen-darwish-syria (última consulta, 10-11-2014).

Gilroy, P. (2000): Between Camps: Race Identity and Nationalism at the End of the Colour Line. Harmondsworth, Penguin.

KANE, J. M. (1996): «The Migrant Intellectual and the Body of History: Salman Rushdie's Midnight's Children», Contemporary Literature, 37/1 (primavera), en http://www.jstor.org/

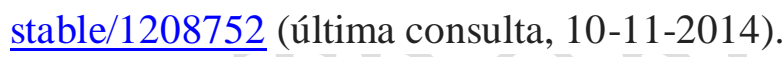

LeJEUnE, P. (1975): «El pacto autobiográfico». Trad. de Ángel G. Loureiro. Suplementos Anthropos, 29, 1996.

RusHDIE, S. (1981): Midnight's Children. Nueva York, Random House, 2006.

- (1988): The Satanic Verses. Londres, Vintage, 2006.

- (2012): Joseph Anton: A Memoir. Londres, Vintage.

(2012): Joseph Anton. México, Mondadori.

SMITH, S. y J. WATSON (2005): «The Trouble with Autobiography: Cautionary Notes for Narrative Theorists», en J. Phelan y P. J. Rabinowitz, eds., A Companion to Narrative Theory. Oxford, Blackwell.

StURrock, J. (1993): The Language of Autobiography. Studies in the First Person Singular. Cambridge, CUP.

SwindELLS, J., ed. (1995): The Uses of Autobiography. Londres / Bristol, Taylor and Francis.

y empujaba los límites del lenguaje, la forma y la posibilidad, para crear la sensación de que el mundo era más grande, más amplio, que antes» (Rushdie, 2012: 679). 